http://dx.doi.org/10.30681/23588403v12i010719

\title{
A ORDEM N-ADJ E ADJ-N EM CORPORA DOS SÉCULOS XVIII E XX DO PORTUGUÊS BRASILEIRO
}

Data de recebimento: $25 / 07 / 2017$

Aceite: 05/09/2017

\author{
Alessandra Emanuelle Macieira SILVA (UFMG) ${ }^{1}$
} Aléxia Teles DUCHOWNY (UFMG) ${ }^{2}$

\begin{abstract}
Resumo: Este trabalho tem como objetivo verificar as ocorrências da ordem N-Adj e Adj-N em corpora do português brasileiro escrito dos séculos XVIII e XX de gênero jornalístico. $\mathrm{O}$ primeiro foi extraído do site Corpus Histórico do Português Tycho-Brahe (GALVES; ANDRADE; FARIA, 2017) e o segundo, do Banco do Português (SARDINHA, 2003) totalizando 100 ocorrências analisadas em cada. Esta pesquisa pretende explicar como a posposição e a anteposição dos adjetivos se relacionam ao tipo textual jornalístico e às motivações que podem ser depreendidas. O trabalho pretende, ainda, estabelecer correlações entre o universal referente à ordem entre nome e adjetivo proposto por Greenberg (1983) e refutado por Dryer (1988). Os dados indicaram que a escolha pela posição do adjetivo é motivada por fatores semântico-discursivos. Este presente estudo diacrônico da posição do adjetivo no sintagma nominal pretende, assim, reafirmar que a língua, de fato, atende à necessidade discursiva.
\end{abstract}

Palavras-chave: Ordem N-Adj. Ordem Adj-N. Posposição. Anteposição.

Abstract: This study had the objective of verifying the occurrences of the N-Adj order and Adj-N order in corpora of written Brazilian Portuguese of $18^{\text {th }}$ century and $20^{\text {th }}$ century of journalistic genre. The first was extracted of the site Corpus Histórico do Português TychoBrahe (GALVES; ANDRADE; FARIA, 2017) and the second one, of the Banco do Português (SARDINHA, 2003) in total of 100 analyzed occurrences of each one. This research had the objective of explaining how the occurrence of preposition and postposition of the adjectives are related to the journalistic text and the motivations that can be investigated. This study had the purpose of establishing correlations between the universal that refers to the order of name and adjective proposed by Greenberg (1983) and refuted by Dryer (1988). The data shows that the choice of the position of adjective is motivated by semantics and discursive factors. This present diachronic study intends to reaffirm that the language, certainly, serves the discursive necessity.

Keywords: Order of N-Adj. Order of Adj-N. Postposition. Anteposition.

\footnotetext{
${ }^{1}$ Graduanda em Letras - Bacharelado em Linguística, Universidade Federal de Minas Gerais, Belo Horizonte, Brasil, alessandraems@gmail.com

2 Doutora em Estudos Linguísticos, Universidade Federal de Minas Gerais, Belo Horizonte, Brasil, alexiateles@letras.ufmg.br
} 


\section{Introdução}

O estudo sobre a ordem dos constituintes de uma sentença foi objeto de investigação de linguistas em diferentes épocas, a fim de demonstrar como tal ordem pode influenciar a ocorrência de elementos como nome, adjetivo e pronomes. Greenberg (1983) realizou um estudo de grande relevância sobre os tipos de línguas (VO ou OV) e a ordem de adjetivos e nome. Com base em uma amostra de 30 línguas, Greenberg (1983) comparou línguas da Eurásia (13), África (7), Sudeste Asiático e Oceania (4), Austrália e Nova Guiné (1), América do Norte (2) e América do Sul (3). A correlação entre as línguas foi feita através da comparação de features (características) e obteve generalizações, que posteriormente foram contestadas. Neste presente estudo, iremos nos ater à formulação de Greenberg (1983) sobre a ordem do adjetivo e nome em relação à ordem SVO, de modo a relacionar o universal proposto pelo linguista e os dados do português brasileiro (PB) e o que influenciaria esta "flexibilidade" do deslocamento do adjetivo em relação ao nome.

Os preceitos que Greenberg (1983) formulou sobre as línguas do mundo são os considerados universais linguísticos. O universal de Greenberg (1983) a ser considerado nesta pesquisa corresponde à formulação de que as línguas OV tendem a ter a ordem N-Adj e VO tendem apresentam Adj-N (GREENBERG, 1983), conforme consta no The World Atlas of Language Structures, WALS (DRYER; HASPELMATH, 2013) ${ }^{3}$ :

Figura 1: Distribuição da ordem S, V, O e ordem Nome e Adjetivo.

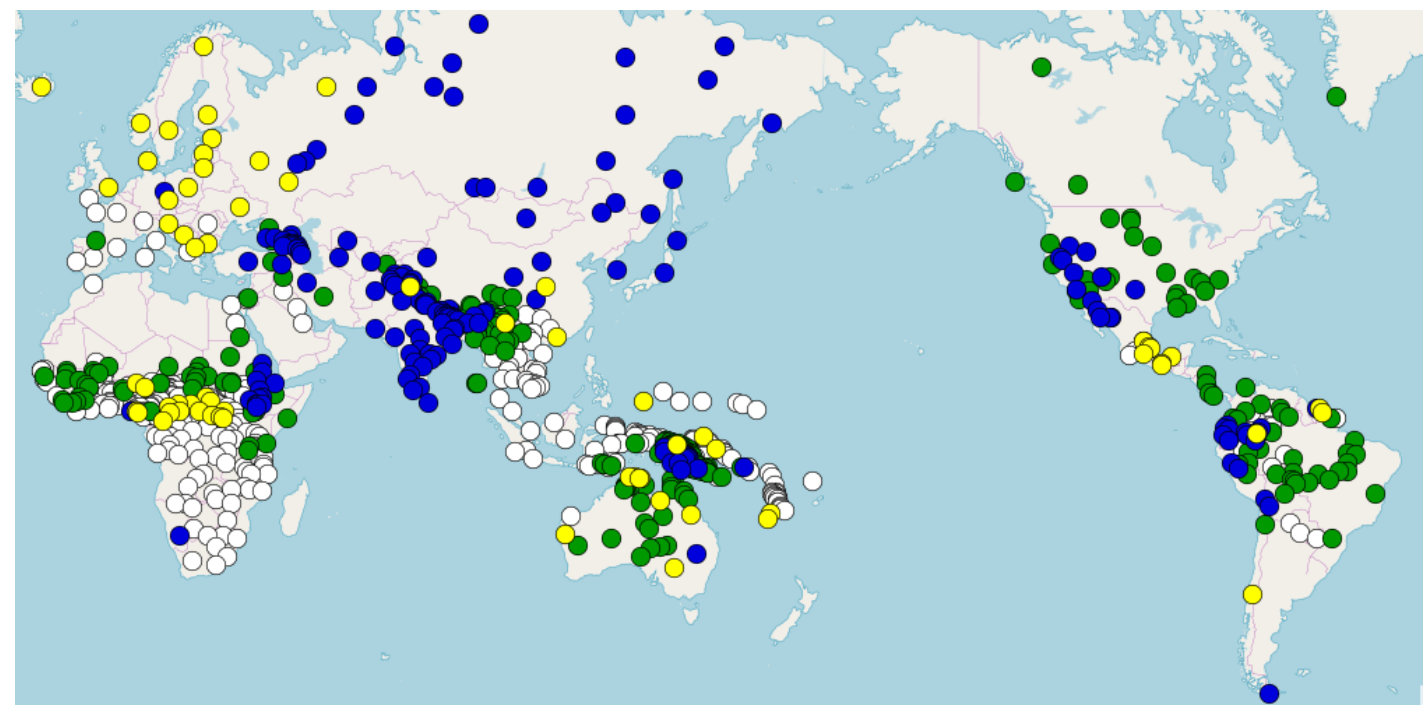

Fonte: DRYER; HASPELMATH (2013).

\footnotetext{
${ }^{3}$ Este Atlas Linguístico possibilita a combinação de características dentre as línguas do mundo e se encontra disponível em < http://wals.info/> (DRYER; HASPELMATH, 2013).
} 
Figura 2: Número de línguas de acordo com a ordem S, V, O e Nome e Adjetivo.

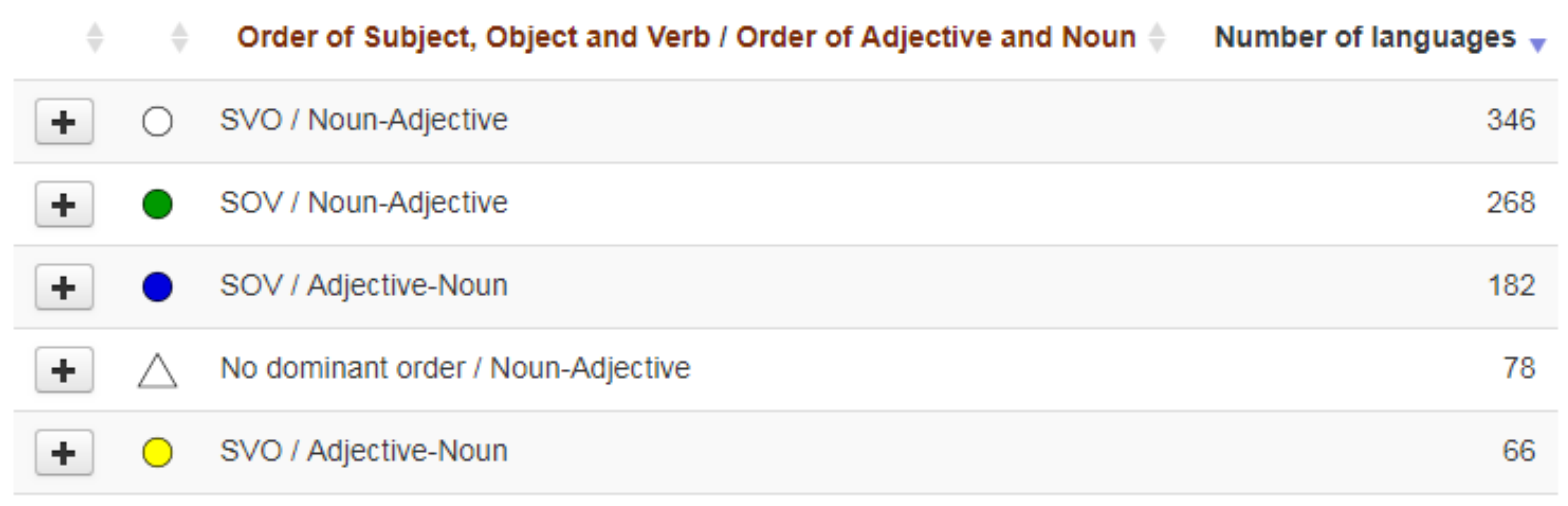

Fonte: DRYER; HASPELMATH (2013).

De acordo com as imagens apresentadas, no Brasil há predominância da ordem SOV e o adjetivo posposto ao nome - o que iremos verificar se realmente ocorre nos corpora aqui adotados. Assim, sendo o português uma língua de ordem SVO, isto é, uma língua de núcleo inicial e preposicional (com o sujeito e verbo iniciando a oração), os estudos de Greenberg (1983) apontariam, provavelmente, a ocorrência posposicional do adjetivo. Contudo, essa correlação não ocorre sempre, como já evidenciou o trabalho desenvolvido por Dryer $(1988)^{4}$ sobre essa ordem nas línguas.

A fim de verificar como esta correlação seria verificada no português brasileiro (PB) por meio do contraste entre dois séculos, selecionaram-se dois corpora de PB escrito: um correspondente ao século XVIII e outro do século XX. O primeiro foi retirado do Corpus Histórico do Português Tycho Brahe (GALVES; ANDRADE; FARIA, 2017) e o segundo foi extraído do corpus do português contemporâneo Banco de Português (SARDINHA, 2003). Desse modo, este presente estudo objetiva demostrar quais as ocorrências da ordem N-Adj ou Adj-N no PB e se houve alguma mudança significativa ou se o uso se manteve constante ao longo dos séculos.

\section{Fundamentação teórica}

A observação das orações adjetivas nos séculos XVIII e XX será pautada na definição de adjetivo abordada, de modo geral, nas gramáticas do português, isto é, um modificador do substantivo que visa caracterizá-lo ou estabelecer relação entre ambos (CUNHA; CINTRA, 2003). A posição do adjetivo na oração não é ainda delimitada em

\footnotetext{
${ }^{4}$ Não iremos nos ater de forma substancial às explicações do estudo de Dryer. Para maiores detalhes, ver Dryer (1988).
} 
estudos sobre essa natureza, visto que, apesar de ser uma língua predominantemente SVO, o PB permite que o adjetivo seja deslocado na oração - o que não possibilita chegar a uma categoria de posição definida. A colocação deste elemento em relação ao verbo, segundo a visão da Gramática Tradicional, é apontada por Cunha (1972) que descreve que a posição estaria relacionada à função adnominal do adjetivo: se este tiver valor denotativo, tende a ocorrer depois do substantivo. Outra definição a esse respeito é apresentada por MIRA et al. (2003) na qual a posição é explicada em relação aos adjetivos modificadores/qualificativos e relacionais. Os primeiros indicam qualidades e não interferem no significado, como em (1) podendo ocorrer em posição pré-nominal ou pós-nominal. Já os últimos restringem e delimitam o que é denotado no substantivo, isto é, se relacionam semanticamente com o substantivo, como em (2) e não seriam flexíveis quanto ao deslocamento, conforme os exemplos abaixo ${ }^{5}$ :

(1) A cidade tem um prédio alto. / A cidade tem um prédio muito alto. / A cidade tem um alto prédio.

(2) Estou assistindo a um filme policial. / *Estou assistindo a um filme muito policial./ *Estou assistindo a um policial filme. / O filme, que estou assistindo, é policial.

Os exemplos evidenciam que a ordem "não permitida" para os adjetivos gera frases agramaticais. Desse modo, o posicionamento deste elemento segue algumas "regras" de colocação. Podemos depreender que a posição pós-nominal está associada à restrição e especificação que o adjetivo confere ao sintagma nominal (MIRA et al., 2003). A posição quanto ao núcleo oracional é adotado por Perini (1996) e Casteleiro (1981) ao indicar que os adjetivos que ocorrem como N-Adj indicam uma interpretação temporária e os que ocorrem como Adj-N tendem a significar uma interpretação de constância (CASTELEIRO, 1981), como por exemplo, "os salários baixos" e "os baixos salários". ${ }^{6}$ Segundo Perini (1996), a colocação do adjetivo é motivada pelo contexto sintático e/ou semântico-discursivo. Entretanto, Serra (2005) observou, posteriormente, que a motivação considera apenas o valor semântico e discursivo do adjetivo.

A tendência de que a mudança sintática pode ocorrer com a inversão de um dos constituintes da oração ao longo do uso na língua será verificada neste estudo. Uma análise

\footnotetext{
${ }^{5}$ Alguns exemplos foram adaptados de Bud'a (2010) a fim de tornar a explicação mais contextualizada na sentença.

${ }^{6}$ Exemplo retirado de Serra (2005).
} 
importante sobre as orações adjetivas foi desenvolvido por Cohen (1979) ${ }^{7}$ e mostrou que no português arcaico e médio a ordem de preferência era a anteposição do adjetivo ao nome. Analisando as ocorrências dos adjetivos, o estudo destacou que a colocação destes na frase pode ser feita por anteposição ou posposição. Assim, por meio da análise dos textos escritos dos séculos XVIII e XX, foi verificado que os valores indicavam o surgimento de alguma mudança em relação ao padrão de posição dos itens lexicais. De todo modo, outros fatores podem fundamentar a preferência em relação à colocação dos adjetivos. Dentre estes, a função estilística como critério para a escolha da posição dos adjetivos foi considerada por Lapa (1968, apud SERRA, 2005, p. 17) ao afirmar que, de acordo com a posição, o adjetivo obtém significação diferente: "quando o adjetivo está logo depois do substantivo, tende a conservar o valor próprio, objetivo, intelectual; quando está antes, tende a perder o próprio valor e a adquirir um sentido afetivo".

A análise dos adjetivos com base em sua ocorrência com determinantes foi desenvolvida por Serra (2005) que, ao analisar os corpora do PB dos séculos XVIII ao XX, propõe que os adjetivos descritivos são os que são mantidos ao longo dos séculos. Serra (2005, p. 107) salienta, ainda, que a "anteposição esteve sempre relacionada: (1) aos adjetivos avaliativos, quer quando o núcleo é imaterial quer quando é material, (2) aos adjetivos de menor peso fônico com relação ao substantivo e (3) aos adjetivos de base nominal”. Contudo, os aspectos sintáticos não são os critérios principais na análise do deslocamento do adjetivo em relação ao nome, conforme verificou o trabalho de Bud'a (2010, p. 232) sobre a posição do adjetivo no sintagma nominal do PB. Neste, foram analisados, além de outros ${ }^{8}$, aspectos semânticos dos adjetivos que revelaram que a anteposição corresponde a uma forma de intensificar o significado, "mas também pode atribuir um valor de inerência a um adjetivo qualificativo ou de expressividade, se o adjetivo é relacional”.

As correspondências entre as ordens N-Adj e Adj-N para o português brasileiro, apontadas pelos estudos aqui citados, demonstram que os universais de Greenberg (1983) não seriam válidos de acordo com a perspectiva diacrônica da língua. Conforme é verificado na literatura, os estudos de tipologia sintática avançaram assim como as línguas, mas os universais de Greenberg (1983) constituem um estudo pioneiro na classificação das línguas do mundo e, portanto, serve de base para pesquisas dessa natureza. $\mathrm{O}$ referente estudo foi

\footnotetext{
${ }^{7}$ Para maiores detalhes sobre o estudo das construções adjetivas, ver Cohen (1979).

${ }^{8} \mathrm{O}$ estudo de Bud'a (2010) relacionou aspectos prosódicos, fonéticos, fraseológicos e sintáticos. Para maiores detalhes, ver Bud'a (2010).
} 
refutado por Dryer (1988) em que o autor mostrava que as correlações indicadas por Greenberg (1983) não são categóricas nas línguas e, sobretudo, não eram fruto de uma dependência sintática, mas sim de um viés areal. Dryer (1988) examinou separadamente as línguas SVO e línguas V-inicial, de modo que observou que as línguas OV na Eurásia tendem a preferir a ordem Adj-N e as línguas OV fora da Eurásia preferem a ordem N-Adj. Desse modo, o estudo de Dryer (1988) destacou que o que ocorria era um viés areal muito forte na Eurásia, sendo que não haveria evidência entre a "ordem do verbo, objeto e a ordem do adjetivo e nome" (DRYER, 1988, tradução nossa). ${ }^{9}$ A fim de estabelecer uma nova explicação, Dryer (1988) propôs as definições de branching (categorias "ramificadas") e nonbranching (categorias não ramificadas). Segundo Dryer (1988), as categorias branching precedem as non-branching, de modo que o adjetivo seria considerado uma categoria não ramificada - e seria colocado antes das categorias não branching. Analisaremos tal perspectiva na seção 5 deste artigo.

\section{Metodologia}

A busca pelas orações adjetivas foi feita no Corpus Histórico do Português Tycho Brahe (GALVES; ANDRADE; FARIA, 2017) ${ }^{10}$ e no corpus do português contemporâneo Banco de Português (SARDINHA, 2003) ${ }^{11}$. Foram selecionados textos escritos referentes apenas a gêneros textuais jornalísticos de modo que a pesquisa não fosse prejudicada por questões estilísticas de gêneros textuais como cartas e narrativas. O gênero jornalístico foi escolhido por possibilitar construções de motivação discursiva, sendo, portanto, possível verificar como a língua atende a tais necessidades na relação N/Adj. Os séculos analisados foram os séculos XVIII e XX devido à disponibilidade online e facilidade de acesso aos textos nos respectivos sites.

Para a manipulação dos dados, gerou-se a lista de frequência das palavras do Banco de Português, a fim de encontrar os adjetivos mais recorrentes. Em seguida, os itens foram procurados na ferramenta de busca do próprio site e contabilizados. Em relação ao Corpus Histórico do Português Tycho Brahe, os dados foram obtidos baixando o corpus anotado sintaticamente em formato .txt e inseridos no software de busca textual AntConc (ANTHONY, 2014) a fim de procurar os adjetivos por meio de uma lista de palavras gerada

\footnotetext{
9 "Between the order of verb and object and the order of adjective and noun" (DRYER, 1988, p. 191).

${ }_{10} \mathrm{O}$ Corpus Histórico do Português Tycho Brahe pode ser acessado em: <http://www.tycho.iel.unicamp.br/corpus/catalogo.html>.

${ }^{11} \mathrm{O}$ corpus do Banco do Português pode ser acessado em: 〈http://www2.lael.pucsp.br/corpora/bp/index.htm>.
} 
pela própria ferramenta. Em sequência foram selecionadas 100 ocorrências dos dois corpora e os dados, quantificados e analisados. Por fim, alguns adjetivos que iriam prejudicar a análise foram desconsiderados, como por exemplo, ilustríssimo e excelentíssimo visto que estes eram usados no século XVIII junto a substantivos próprios, sendo interpretados como justapostos ao nome para expressar cordialidade e não a fim de caracterizar o substantivo: por exemplo, Sua Majestade comprou o palácio do Ilustríssimo e Excelentíssimo Conde da Ribeira.

\section{Análise dos dados e resultados}

A construção sintática das orações adjetivas, como já mencionado, pode ocorrer com o deslocamento do adjetivo em relação ao nome. A fim de comparar as ocorrências nos séculos selecionados, consta a seguir a análise das ocorrências encontradas para os dois períodos.

\subsection{Século XVIII}

Os dados analisados em relação ao século XVIII indicaram uma tendência maior em relação à ordem em que o adjetivo é preposto, como mostra o gráfico abaixo:

Gráfico 1: Ordem N-Adj e Adj-N no século XVIII.

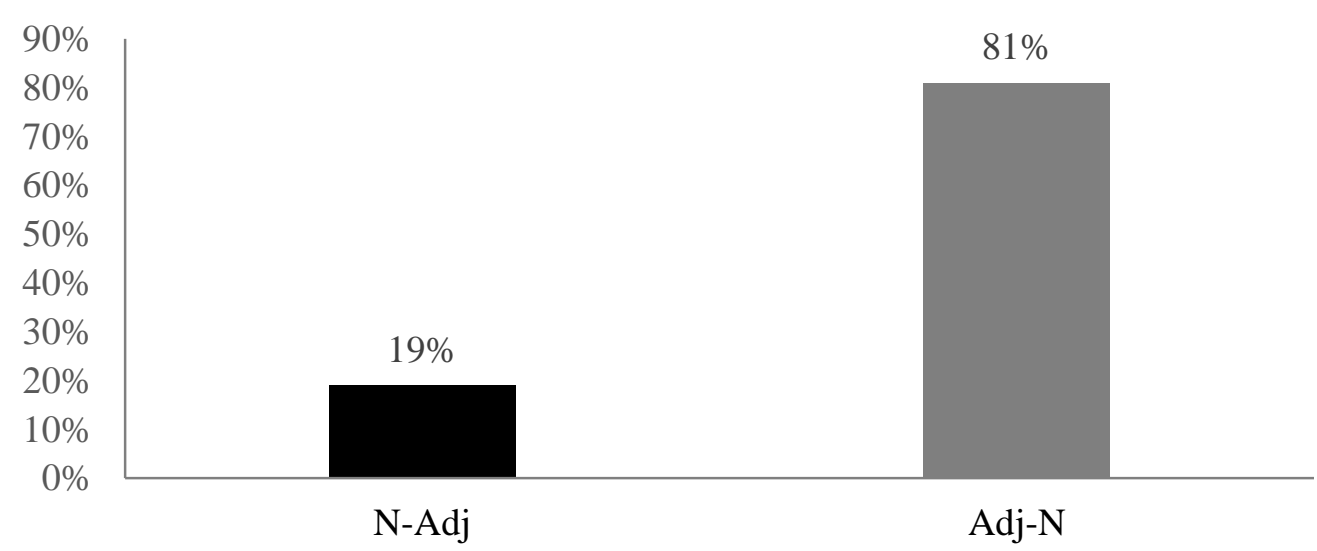

A preferência pela ordem Adj-N nos jornais da época mostra certa subjetividade do escritor perante as informações apresentadas por este. Neste período, os adjetivos eram usados em textos jornalísticos para caracterizar os assuntos da Monarquia e, desse modo, os escritores os utilizavam como forma de descrever as situações e acontecimentos a fim de fornecer informações à Corte, para estabelecer uma conexão entre a opinião do escritor e o conteúdo por ele apresentado. Assim, sob a ótica de Serra (2005, p. 18), a anteposição confere maior subjetividade e juízo de valor “ao conteúdo semântico do sintagma nominal”. Logo, no 
contexto histórico deste século, a fim de promover maior proximidade com a nobreza, o uso de adjetivos antepostos seria mais comum, tal como mostra os exemplos:

(3) Ele recebeu os cavalos rejeitados do Regimento Número 10, e está presentemente a todo o ponto de vista em melhor estado do que este.

(4) As Cartas de Roma referem, que deixando o Bispo eleito do Porto Frei José d'Évora um grande trem de fato entregue a um Religioso Franciscano seu Secretário, com a recomendação de o fazer conduzir para esta Corte [...].

(5) A uma autoridade [...] sucedeu um governo que toda a Nação desejava por sua maior analogia com as nossas leis e nossos costumes, e por sua maior concordância com a dificuldade e urgência das circunstâncias, que nos rodeiam.

Podemos analisar os exemplos com base na proposta de MIRA et al. (2003) em que os autores indicam que os adjetivos em anteposição representam uma relação direta com o substantivo. Em (3), é perceptível que o adjetivo melhor é classificado como modificador, pois qualifica o nome que o segue (estado), assim como em (4) e (5). Desse modo, a anteposição serve como uma forma de estabelecer uma predicação ao substantivo e por isso o adjetivo tende a ocorrer anteposto por uma escolha semântica. Contudo, algumas ocorrências indicaram que o verbo que introduz a frase adjetiva era separado por uma sequência descritiva:

(6) O Excelentíssimo e Reverendíssimo Bispo do Porto mandou agora de presente ao Papa 12 caixotes, e se presume, que cheios de louça da Índia [...] e tantos pássaros de cores, e cantos diferentes; doze papagaios de diferentes espécies, e 6 macacos de diverso feitio.

Em (6), podemos notar que o verbo que introduz o sintagma adjetival está introduzindo outros sintagmas de mesmo tipo: mandou tantos pássaros de cores, mandou tantos pássaros de cantos diferentes, mandou doze papagaios de diferentes espécies. A posposição em cantos diferentes e a anteposição em diferentes épocas correspondem a adjetivos modificadores. Contudo, a maior parte das ocorrências, como já citado, indica a preferência pela preposição do adjetivo, o que é explicado pelo contexto social da época. $\mathrm{O}$ fato de o adjetivo anteposto conferir valor subjetivo ao sintagma nominal é próprio do texto opinativo e parcial do século XVIII, em que os jornalistas, com o objetivo de agradar e servir à Corte preenchiam seus textos com comentários - o que é uma marca da anteposição.

\subsection{Século XX}


O uso de determinado item ou construção sintática em períodos históricos diferentes indica que, de fato, a língua atende às necessidades comunicativas. Ao contrário do que é registrado no período monárquico, no século $\mathrm{XX}$ a preferência dos jornalistas era por construções com posposições do adjetivo. Podemos associar essa tendência ao fato de a posposição representar uma forma "neutra" de remeter ao sintagma nominal, sendo, portanto, mais objetivo (BARBOSA, 1822, apud BERLINCK, 1989). O gráfico abaixo mostra a quantificação dos dados neste século:

Gráfico 2: Ordem N-Adj e Adj-N no século XX.

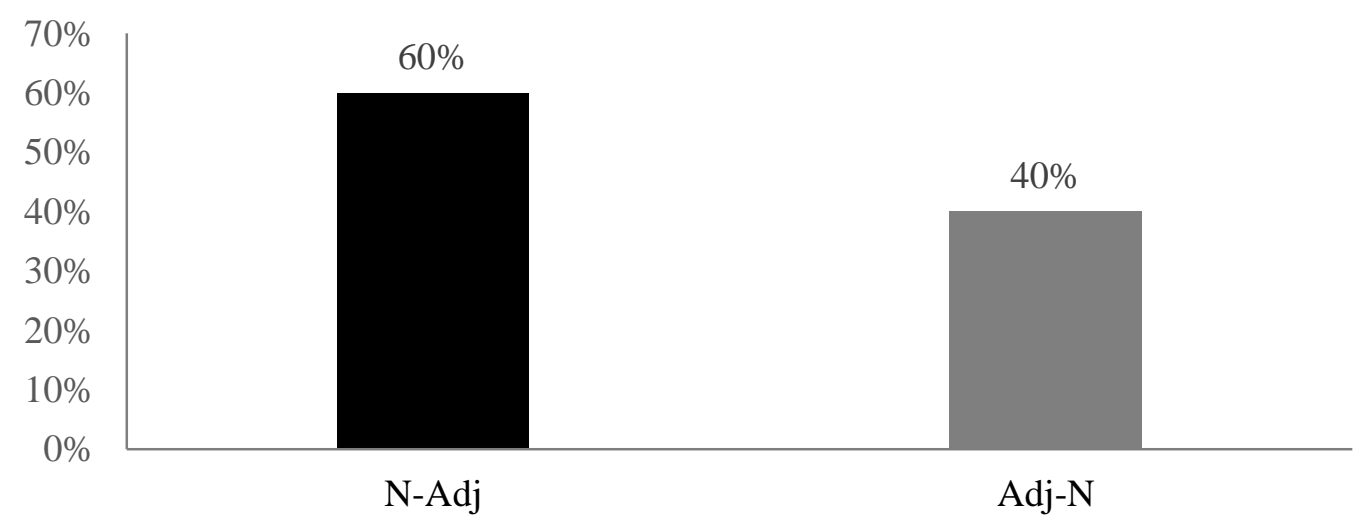

A escolha pela posição do adjetivo após o nome indica a função comunicativa dos jornais desse período, visto que não havia mais monarquia no Brasil - o que não "limitava" a publicação mais objetiva dos escritores. Desse modo, visando à neutralidade ao emitir informações, os jornais, em sua maioria, apresentavam textos em que os sintagmas nominais eram apenas descritos, sem nenhum juízo de valor - constatando, de fato, a imparcialidade característica do gênero jornalístico, como indicam os exemplos a seguir:

(7) [...] a fenformina nunca foi utilizada como tratamento principal e único do diabetes mellitus.

(8) [...] sempre mais fortes por uma desigualdade grande.

(9) Salvador também organizaram uma programação especial para marcar o início do novo milênio.

(10) [...] hoje Eliseu Padilha, e atualmente sua função principal é carregar documentos no ministério.

Nos exemplos podemos perceber que a colocação dos adjetivos logo após os nomes corresponde aos adjetivos relacionais visto que restringem a informação do substantivo sem acrescentar opinião e juízo de valor, apenas limita o significado ao nome. $\mathrm{O}$ adjetivo forte em 
(8) foi desconsiderado por não estar encaixado sequencialmente a um nome e, portanto, não é possível analisar a ordem N-Adj. Em (7) e (8), os adjetivos principal, único e grande por estarem em posição posterior ao nome, parecem expressar uma relação mais imparcial com o sintagma nominal - o mesmo é verificado para os adjetivos especial em (9) e principal em (10), que é contrastado com o adjetivo novo em (9) que se encontra em anteposição em nome. Conforme Carneiro (1992, apud MONNERAT, 2003) os adjetivos objetivos tendem a uma "autosuficiência informativa" e assim, não há necessidade de gerar uma dependência explicativa entre o nome e o adjetivo. De fato, a "relação entre o substantivo e um adjetivo relacional, dado que constituem uma unidade semântica, é mais forte do que a relação entre o substantivo e um adjetivo qualificativo" (BUĎA, 2010 p. 227). Logo, assim como nos textos do século XVIII, a motivação é semântica e não sintática.

\section{Conclusões}

A análise da ordem N-Adj e Adj-N nos séculos XVIII e XX indicou que fatores semântico-discursivos motivam a escolha entre preposições e posposições. A primeira escolha é caracterizada por adjetivos modificadores e visa a uma parcialidade maior entre o escritor e o que é descrito em seu texto, dando ênfase à subjetividade. Já a segunda estratégia utiliza adjetivos relacionais que imprimem maior objetividade e uma informação mais concreta devido à relação entre nome e adjetivo ser mais "direta", restringindo a extensão do significado do substantivo.

Desse modo, podemos perceber que "a escolha da ordem do adjetivo com relação ao núcleo" não é motivada por fatores "estritamente gramaticais, como a função sintática do SN" (SERRA, 2005, p. 21). Em relação ao universal 16 de Greenberg (1983), este não é atestado nos dados dos corpora visto que o PB apresenta as duas ordens em períodos diferentes, sendo que a afirmação de que línguas SVO normalmente apresentam os adjetivos pospostos ao nome (GREENBERG, 1983) não é verificada. A proposta de Dryer (1988), desse modo, é mais consistente, visto que considera o adjetivo como categoria non-branching (não ramificada), pois possui estrutura sintática simples e, geralmente, corresponde a apenas uma palavra. Logo, a tendência em línguas VO, conforme Dryer (1988) seria as categorias nonbranching precederem as categorias branching. Apesar de ser válida em outras instâncias, essa correlação é identificada no PB por meio dos dados desta pesquisa apenas em relação ao século XVIII. 
Os dados, por conseguinte, mostraram que o fator discursivo é o principal definidor quanto à escolha da preposição ou posposição de modo que a ordem Adj-N, atestada no século XVIII, indicaria um objetivo mais avaliativo e abstrato enquanto a ordem N-Adj indica um afastamento entre o jornalista e o texto por meio da objetividade e pura descrição do conteúdo, verificada nos dados do século XX. De fato, as ocorrências analisadas nesta pesquisa não constituem uma quantidade realmente representativa, mas sendo uma amostra balanceada, podemos de todo verificar semelhanças e diferenças entre os períodos. Por meio deste estudo, pode-se chegar a um fator geral tal como afirma Serra (2005, p. 22) "quanto mais opiniões e comentários, maior a quantidade de adjetivos precedendo o núcleo". Dessa forma, o gênero textual contribui para o posicionamento do adjetivo no sintagma nominal e conforme verificado nos dados aqui apresentados, não é motivado sintaticamente.

\section{Referências}

ANTHONY, L. AntConc. Versão 3.4.3. [Computer Software]. Tokyo, Japan: Waseda University, 2014. Disponível em <http://www.laurenceanthony.net/>._Acesso em: 30 ago. 2018.

BARbOSA, J. S. Grammatica Philosophica da Lingua Portugueza ou principios da grammatica geral applicados á nossa linguagem. Lisboa: Typographia da Academia das Sciencias, 1822. Disponível em: <https://bibdig.biblioteca.unesp.br/handle/10/6903>. Acesso em: 30 ago. 2018.

BERLINCK, R. A. A construção V SN no português do Brasil: uma visão diacrônica do fenômeno da ordem. In: TARALLO, F. (Org.) Fotografias Sociolinguiísticas. Campinas: Pontes, 1989. p. 95-112.

BUĎA, J. As Lacunas da Ortografia Portuguesa. 2010. 46f. (Tese de Bacharelado) Universidade Masaryk, Faculdade de Artes, Brno, 2010.

CALLOU, D.; NASCIMENTO, M.; SERRA, C.; BARBOSA, A.; BARRETO, F.; AMARO, R.; PEREIRA, L.; MENDES, A.; VELOSO, R. A posição do adjetivo no sintagma nominal: duas perspectivas de análise, 2002. In: BRANDÃO, S.; MOTA, M.A. (Org.). Análise Contrastiva de Variedades do Português. Rio de Janeiro: In-Fólio, 2003. p. 11-35.

CARNEIRO, A. D. O adjetivo e a progressão textual. Letras \& Letras, Uberlândia, v.8, p. 31-36, jun. 1992.

CASTEleIRO, J. M. Sintaxe Transformacional do Adjectivo. Lisboa: Instituto Nacional de Investigação Científica, 1981. 
COHEN, M. A. O posicionamento do adjetivo no sintagma nominal português. Boletim do Centro de Estudos Portugueses, Belo Horizonte, n.12, p.58-62, 1979.

CUNHA, C. F. Gramática da língua portuguesa. 3. ed. Rio de Janeiro: Editora Bernardo Álvares, 1972.

CUNHA, C; CINTRA, L. Nova gramática do português contemporâneo. 3. ed. Rio de Janeiro: Nova Fronteira, 2003. 748p.

DRYER, M. S. Object-Verb Order and Adjective-Noun Order: Dispelling a Myth. Lingua, Elsevier, v.74. n.2-3, p. 185-207, 1988.

DRYER, M. S; HASPELMATH, M. (Eds.), 2013. The World Atlas of Language Structures Online. Leipzig: Max Planck Institute for Evolutionary Anthropology. Disponível em: <http://wals.info/>. Acesso em: 23 jun. 2018.

GAlVES, C.; ANDRADE, A. L.; FARIA, P. Tycho Brahe Parsed Corpus of Historical Portuguese, 2017.

Disponível em: <http://www.tycho.iel.unicamp.br/ tycho/corpus/texts/psd.zip. Acesso em: 20 jun. 2018.

GREENBERG, J. H. Some universals of grammar with particular reference to the order of meaningful elements. In:

MIT Press, 1983. p. 73-113. . (Ed.). Universals of Human language. Cambridge, MA:

LAPA, M. R. Estilística da língua portuguesa. Rio de Janeiro: Livraria Acadêmica, 1968.

MIRA, M. H.; BRITO, A. M.; DUARTE, I.; FARIA, I. H. Gramática da língua portuguesa. Lisboa: Caminho, 2003. 417p.

MONNERAT, R. S. M. Processos de intensificação no discurso publicitário e a construção do ethos. In: PAUliUKOniS, M. A. L.; GAVAZZI, S. (Orgs.) Texto e Discurso: mídia, literatura e ensino. Rio de Janeiro: Lucerna, 2003. p. 97-109.

PERINI, M. A. Gramática descritiva do português. 2 ed. São Paulo: Ática, 1996. 308p.

SARDINHA, T. B. Banco do Português, 2003. Disponível em < http://www2.lael.pucsp.br/corpora/bp/index.htm>. Acesso em: 20 jun. 2018. 
SERRA, R. C. A Ordem dos Adjetivos no Percurso Histórico: variação e prosódia. 2005. 153 f. Dissertação (Mestrado em Língua Portuguesa) - Faculdade de Letras, Universidade Federal do Rio de Janeiro, Rio de Janeiro, 2005. 